\title{
A FORMAÇÃO DO OUVIDOR-EDUCADOR E SEUS DESAFIOS
}

\author{
Maria Ivoneide de Lima Brito ${ }^{1}$ \\ Larissa dos Santos Aguiar ${ }^{2}$
}

\begin{abstract}
Resumo
O presente artigo se propõe a abordar o desafio de ser Ouvidor, refletindo acerca de alguns saberes necessários a uma atuação de qualidade e a uma prática educativa eficaz a fim de tornar o atendimento nas Ouvidorias o mais humano possível, ao responder a algumas inquietações: Por que eu atendo? O que represento? Como devo atuar? A quem atenderei? Reconhece-se, assim, a importância dessa tarefa, bem como a necessidade de o profissional valorizar a formação continuada e estar atento à implementação de novas habilidades, competências e tecnologias provenientes de ou para a sua atuação no contexto das Ouvidorias das universidades públicas federais.
\end{abstract}

Palavras-chave: Ouvidor. Educador. Formação Continuada. Universidade.

DOI:10.37814/2594-5068.2019v2.p119-129

1 Doutoranda do Programa de Pós-Graduação em Ciências e Tecnologias em Saúde da Faculdade de Ceilândia (UnB/FCE). Mestra em Educação pela Universidade de Brasília (2013). Especialista em Gestão Universitária pela UnB (2011) e em Linguística e Língua Portuguesa pela Faculdade da Terra de Brasília (2006). Graduada em Pedagogia, com ênfase em Orientação Educacional (2008), e em Letras pela Faculdade da Terra de Brasília (2003). Ouvidora da Universidade de Brasília. Professora voluntária no Curso de Terapia Ocupacional (FCE), bem como no Programa de Extensão Universidade do Envelhecer (UniSer) - (FCE). (www.ouvidoria.unb.br) (ouvidoria@unb.br.) 2 Mestranda em Educação Profissional pela Faculdade de Educação da Universidade de Brasília. Licenciada em Letras, Português e Respectivas Literaturas pela Universidade Católica de Brasília (2003). Possui Aperfeiçoamento em Redação e Revisão de Textos pela Universidade de Brasília (2007). Pós-Graduada em Língua Portuguesa pela Universidade Salgado Oliveira-RJ (2006) e Pós-Graduação lato sensu em Letras pela Universidade de Brasília (2008). Atua na área de revisão e padronização de textos acadêmicos e publicitários desde 2003. É servidora pública federal do Quadro de Pessoal da Fundação Universidade de Brasília desde 2012, atuando como Assessora Técnica da Ouvidoria da UnB e Ouvidora da UnB substituta. (www.ouvidoria.unb.br) (ouvidoria@unb.br.) 


\section{Abstract}

The present article proposes to address the challenge of being a listener, reflecting on some knowledge necessary for a quality performance and an effective educational practice to make attendance in Ombudsman offices as human as possible, when answering some questions: Why do I answer? What do I represent? How should I act? Who will I attend? Thus, the importance of this task is recognized, as well as the need for the professional to value continuing education and be aware of the implementation of new skills, competencies and technologies from or for his work in the context of the Ombudsman's offices of federal public universities.

Keywords: Ombudsman. Educator. Continuing Education. University. 


\section{INTRODUÇÃO}

$\mathrm{Na}$ atual conjuntura da Administração Pública e, por conseguinte, no contexto da educação superior e ainda das universidades públicas federais, um dos maiores desafios é o de ser Ouvidor, tendo em vista que se trata de um sujeito que deve assumir a função de gestor, de orientador e de educador, comprometido com a arte de escutar e, acima de tudo, de resgatar a autonomia intelectual e o pluralismo de ideias dos manifestantes, ou, também, do cidadão que é atendido, estando, sempre, habilitado a transpor as barreiras da diferença, da adversidade e a enfrentar as dificuldades intrínsecas à sua atuação, capacitando-se como ator social eficiente, eficaz, mas, sobretudo, mais humano, mediante a implementação de um processo sólido e específico: sua formação continuada e os saberes necessários a uma atuação de exímia qualidade.

$\mathrm{O}$ ato da escuta e da comunicação e da interlocução sempre foi importante no decorrer da história, em particular na sociedade contemporânea, produtivista, tecnológica, cibernética e multifacetada. Por esse motivo, o Ouvidor, para ser mais eficiente, deve reconhecer o valor de sua tarefa, preparar-se com amplitude, esforçar-se, estudar o contexto em que está inserido, a legislação imbricada e vigente em sua área de atuação e o seu objeto de instrução e, por que não, sua razão de ser: o manifestante.

Esse processo implica entender todos os trâmites que estão intrinsecamente engendrados nesse ato de escutatória, que, na práxis, representa e perpassa o processo de aprendizagem, mediante o domínio e o manuseio de certa variedade de métodos e técnicas de atendimento, o planejamento e a estruturação de suas ações e, sobremodo, o atender com calor no coração.

Atender com calor no coração nada mais é que fazê-lo com um olhar de acolhimento e de alteridade, aqui compreendida como o espaço do respeito e de diálogo do outro, abdicando-se do protagonismo da fala e colocando o outro enquanto personagem principal, o que pode ser comprovado no excerto de um dos poemas de Rubem ALVES (2018): "não é bastante ter ouvidos para ouvir o que é dito. É preciso também que haja silêncio dentro da alma".

Nessa mesma direção, tem-se que o processo de escutatória, explicitado no contexto de atendimento das Ouvidorias, é um dos grandes desafios do profissional em questão, sendo-lhe necessário trabalhar seu silêncio, para que na escuta, no espaço dos ditos, façam-se notórios os não ditos, ou que o contrário seja ressaltado e que reverbere a edificação de um espaço de questionamento e de acolhimento de solicitação, nos mais diversos âmbitos. Processo no qual o ator principal seja o outro e sua fala, cujo papel da escuta sensível seja exaltado, embora essa ação seja, sem dúvida, um grande desafio, conforme cita Rubem ALVES (2018):

Sempre vejo anunciados cursos de oratória. Nunca vi anunciado curso de escutatória. Todo mundo quer aprender a falar. Ninguém quer aprender a ouvir. Pensei em oferecer um curso de escutatória. Mas acho que ninguém vai se matricular.

Os Ouvidores devem ser sujeitos com alma de poeta. Possuidores de um coração gigante fascinado pela alteridade e que, imbuídos da condição de homem-ferramenta, buscam respostas às perguntas e inquietações de seu cotidiano, desmistificando e desmitificando seu ambiente de trabaIho, seja na condição de Ombudsman, como legítimo representante do cidadão, seja no exercício de 
seu modus operandi o ato de representar sua instituição - ao passo que the mostra suas fragilidades e potencialidades -, ou ainda na essência de seu status quo, a construção diária de sua rotina de trabalho.

\section{SABERES NECESSÁRIOS À FORMAÇÃO DO OUVIDOR-EDUCADOR}

Nesse contexto, Paulo FREIRE (2018) - exímio educador brasileiro, pensador comprometido com a vida, com o método, com a prática da liberdade, com o biografar-se, com o existenciar-se e com o historicizar-se do cidadão (o aprendente) e, ainda, do próprio educador, papel cuja vestimenta é perfeita para o Ouvidor, denominado, doravante, Ouvidor-Educador, a saber: um profissional que, no auge de sua atuação, na prática, fomenta o papel da Ouvidoria enquanto "Pedagogia da Administração Pública" - notifica que, para que haja uma educação de qualidade, em particular na área da educação superior, na qual estejam cultivados os vários saberes necessários à prática educativa transformadora, são indispensáveis ao educador e, por que não, ao Ouvidor, os seguintes atributos e/ou atitudes: estabelecer uma pedagogia administrativa - o que, no contexto deste artigo, implica um espaço de atuação que tenha o ser humano como sujeito ativo e passivo, aquele que executa e sofre a ação -, fundada na ética, no respeito à dignidade e à autonomia do cidadão, visto que o Ouvidor-Educador resplandece como reflexo para aqueles que o rodeiam e o procuram, visando contribuir para a construção de um espaço universitário que resgate e valorize o papel social da equidade e de coesão social, enquanto fonte de reflexão social e proposições para o País.

Ter consciência entre o saber-fazer e o saber-ser-pedagógico, ou seja, estar cônscio de que atuar, executar suas funções, é muito mais do que puramente treinar suas habilidades e competências, mas também as da equipe que o acompanha no desempenho de suas atribuições. É permitir a construção de uma cidadania plena, tanto de sua parte quanto da parte da equipe de trabalho e, por fim, do próprio manifestante que procura os serviços da Ouvidoria.

Ter formação científica, comprometimento com a pesquisa, já que não há relação de aprendizagem sem pesquisa e pesquisa sem ensino, pois é oportuno que o Ouvidor obtenha conhecimentos precisos a respeito da aquisição da linguagem, da ideologia, das técnicas e das práticas de leitura, da escrita, de comunicação, de métodos de resolução de conflitos, entre outros tantos conhecimentos provenientes dos normativos e das legislações vigentes que abarcam seu contexto de atuação. Essa formação também inclui correção ética, respeito ao outro, coerência, capacidade de viver e de aprender com o diferente, não permitindo que as diferenças sejam as justificativas para uma educação de pior qualidade. Portanto, o Ouvidor-Educador deverá rejeitar qualquer tipo de discriminação, sendo-Ihe notória a cautela, a discrição, o respeito às diferenças e à diversidade, a ausculta sensível.

Todos os saberes supracitados compõem um itinerário formativo para o Ouvidor-Educador, sendo, talvez, seu grande desafio buscá-los e fazê-los presentes em sua atuação diária, contemplando, desta feita, alguns dos pilares da educação, o de aprender a aprender e aprender a fazer.

Ainda segundo FREIRE (2018), é relevante executar reflexão crítica (criticidade) acerca da relação teoria/prática, visto que quem forma se forma e re-forma ao formar, pois quem ensina aprende 
ao ensinar e quem aprende ensina ao aprender, ou, parafraseando esse entendimento do educador citado, quem atende, aprende ao atender e quem é atendido ensina ao receber o atendimento. Isso posto, com a premissa de que cada caso acolhido e recepcionado em uma Ouvidoria universitária transforma-se em um "case", abre-se, portanto, um leque de formação e aprendizagem inigualável, o que exige, entre tantos outros aspectos, imparcialidade, confidencialidade, integridade e, ainda, sensibilidade.

Interessante compreender que atender e, grosso modo, ouvir exige rigorosidade metódica, mediante o ato de incentivar a capacidade crítica do sujeito que fala, sua curiosidade, sua insubmissão e liberdade de expressão, ou não, e seu anseio pelo novo, ou, tão somente, por uma resposta frente ao velho caos que, por vezes, o rodeia em uma situação inerte. E que esse ato de escuta sempre requer respeito à leitura de mundo do cidadão, estimulando-o a perguntar e a refletir sobre a pergunta de sua situação-problema e sua posterior resposta, conjecturando, comparando, apreendendo e aprendendo, esmiuçando sua inquietação e sua manifestação e ressaltando sua liberdade de narrá-la, de dizer. Ato que na prática se configura como o entrelaçar de diálogos e saberes para a construção de práticas salutares, o que pode ser mais bem visualizado na fala de SANTOS (2002):

Essa credibilidade contextual deve ser considerada suficiente para que o saber em causa tenha legitimidade para participar de debates epistemológicos com outros saberes, notadamente o saber científico. A ideia central da sociologia das ausências neste domínio é que não há ignorância em geral nem saber em geral. Toda a ignorância é ignorante de um certo saber e todo o saber é a superação de uma ignorância particular. Deste princípio de incompletude de todos os saberes decorre a possibilidade de diálogo e de disputa epistemológica entre os diferentes saberes. O que cada saber contribui para esse diálogo é o modo como orienta uma dada prática na superação de uma certa ignorância. O confronto e o diálogo entre os saberes é um confronto e diálogo entre diferentes processos através dos quais práticas diferentemente ignorantes se transformam em práticas diferentemente sábias.

É preciso que ele entenda que a formação e a atuação do Ouvidor exigem estética - ou seja, a compreensão de que o homem se expressa de várias formas, mediante uma beleza que lhe é peculiar, o que será refletido mediante seu próprio testemunho (suas ações) - e apreender a relação de como o seu espaço de trabalho e sua atuação estão fomentados e refletidos nos demais espaços de trabalho e de aproximação com o outro. Na prática, objetiva-se levar em consideração, por exemplo, sua condição de servidor público, mediante a análise de suas atitudes e de seus pensamentos que, para os demais, podem funcionar como um espelho ético do Ouvidor e, desse modo, da Ouvidoria, o que se dá por meio da execução de uma ação educativa que, segundo RIOS (2006), abranja a dimensão técnica, política, estética e moral, visando competências inovadoras, uma práxis criadora. Ato que coaduna com o seguinte pensamento: "seres relacionais que somos, educamo-nos, educamos outros e pelos outros somos educados".

Ao Ouvidor-Educador é necessário, ainda, executar uma tarefa oportuna: a prática-crítica do ato de atender, de acolher, de formar e autoformar-se, o que permite a ele, à equipe de trabalho na qual esteja inserido e ao cidadão que é atendido que se assumam como seres sociais e históricos, pensantes, comunicantes, transformadores, criadores de sua própria realidade e da do outro, capazes de produzir e disseminar conhecimento, emancipando-se, cada vez mais, mediante o papel transformador da educação. 
Necessita o Ouvidor compreender que o processo educativo permanece inacabado, graças à construção contínua do ser humano e de sua eterna busca, e que, nesse contexto, venha a agir, sempre, com bom senso, humildade, tolerância e luta em defesa dos direitos do outro, conhecendo as diferentes dimensões que caracterizam a essência da prática pedagógica, por intermédio de uma prática libertadora e emancipadora, embasada nas qualidades acadêmica, técnica, política, científica e social.

O Ouvidor altero e bem-sucedido carece ser resiliente - dono da capacidade de se recobrar facilmente ou se adaptar à má sorte ou às mudanças que lhe são tão pertinentes em seu cotidiano de reclamações e denúncias -, prudente, virtuoso, competente, íntegro, generoso e cheio de esperança, mediante a convicção de que a construção de uma nova realidade, mais relevante, mais eficiente, mais efetiva e eficaz, ato contínuo, é um processo árduo, áspero, todavia possível. Ele deve acreditar que esse aprender pode trazer mudanças duradouras e essenciais que intervêm na realidade e geram novos saberes que interagem com partes da realidade, mas, ao mesmo tempo, abarcam uma visão da totalidade, da coletividade, do conjunto.

Para que seu atendimento se torne eficaz, é cabível que o referido profissional tenha uma escuta sensível para com o cidadão, a fim de que, mediante esse escutar, construa-se um diálogo que possa contribuir para que o manifestante assuma o papel de sujeito da produção de sua inteligência e intersecção no mundo.

$\mathrm{O}$ atender exige querer bem ao outro por meio da afetividade - e seu processo de integração com o meio, com o outro -, da dedicação, do entusiasmo, da hombridade e da alteridade, pois a missão de acolher envolve não apenas a mente, o intelecto, mas também o coração. Se o coração do Ouvidor-Educador estiver envolvido, ele certamente levará a cabo o seu trabalho como missão ímpar, e os cidadãos sentirão isso e, salvo exceção, reagirão favoravelmente. Isso posto não no sentido de emitir juízo de valor acerca do problema em si, mas no sentido de comprometer-se com a causa e the buscar uma solução.

No limiar de sua atuação, é mister destacar que o Ouvidor deve compreender o papel da afetividade no desenvolvimento das relações com o outro; não no sentido de emitir parecer sobre o problema do outro, conforme já pontuado, visto que o Ouvidor deve agir com imparcialidade e não emitir juízo de valor; mas no sentido de enxergar com os "óculos" do outro, de procurar buscar a solução, nas instâncias devidas, com um olhar de sensibilidade; um atendimento que transmita segurança e acolhimento nas relações interpessoais e na abordagem de forma inclusiva, integrada e humanizada. Na prática, cada atendente deveria se nortear, inicialmente, pela seguinte pergunta: como tornar esse atendimento o mais humano possível?

Não com o olhar das tecnologias duras, ou leve-duras, mas com a visão das tecnologias leves (MERHY, 2002), as quais estão embasadas nas relações, na receptividade, na gestão de serviços e que consideram as diferenças individuais e comportamentais, tão peculiares ao ser humano e à sua qualidade de vida, e, nesse limiar, respeitando-se todos os aspectos dialéticos que o rodeiam.

\section{A ATUAÇÃO DE UM OUVIDOR-EDUCADOR E SUAS INQUIETAÇÕES}

A motivação da atuação de um Ouvidor está diretamente associada ao seu comportamento pe-

124 | Revista Científica da Associação Brasileira de Ouvidores/Ombudsman - Ano 2 - nº 2 - 2019 
rante a equipe, ao contexto universitário e, sobremodo, ao cidadão que é atendido, ao modo como prepara o acolhimento e desenvolve suas ações, ao seu relacionamento com os colegas, à fidelidade à missão da Ouvidoria, à fidelidade à instituição a qual presta serviços e ao êxito que possa ter no exercício de seu ministério, objetivando contribuir para a melhoria institucional e, ainda, para a melhoria na esfera do serviço público, como um todo.

O que represento? Como me vejo e como o outro me vê no contexto em que estou inserido? O profissional em questão deverá estar familiarizado com a história, a geografia, o contexto dialético de seu espaço de trabalho e atuação profissional, a importância social da instituição em que atua, tendo domínio de seus normativos internos, das principais questões que o rodeiam e dos prováveis deslindes, dos assuntos mais polêmicos e centrais que estão ocorrendo no transcurso de seu cotidiano.

Como devo atuar? Esse questionamento deverá ser o alicerce para o preparo minucioso de sua formação acadêmica e/ou profissional e para a postura ou papel que o Ouvidor assume perante a comunidade que o envolve e, em suma, com o manifestante que procura o atendimento no âmbito da Ouvidoria de sua lotação.

Por conseguinte, o Ouvidor-Educador deverá ressaltar a seguinte inquietação: a quem atenderei? Ele deverá ter em mente seus alvos e conhecer o perfil da comunidade a ser atendida, os discentes, os docentes, os técnico-administrativos, já que o conhecimento acerca dos atores sociais poderá guiar o Ouvidor no âmbito de seu atendimento e atuação e no seu relacionamento com o cidadão. Essas prerrogativas, certamente, permitirão a ele aperfeiçoamento constante.

Para além das respostas aos questionamentos supracitados, ser empático ou altero é outra qualidade necessária ao Ouvidor de sucesso, pois, colocando-se no lugar do outro, sentindo como o outro, é possível visualizar suas dificuldades, carências e anseios como cidadão e sujeito social do mundo. Nesse contexto, o representante do cidadão deverá atender de modo paciente e sensível, conquistando-lhe a atenção, estabelecendo pontos de contato, encorajando-o a utilizar seu espaço de fala, de controle e de participação social, na construção de uma pedagogia democrática, entre outras possibilidades e ações. Nessa direção, torna-se essencial a percepção de que o homem é um sujeito complexo e que se apresenta em constante interação social, conforme as palavras de MORIN (2014):

Portanto, é preciso ensinar a unidade dos três destinos, porque somos indivíduos, mas como indivíduos somos cada um, um fragmento da sociedade e da espécie Homo sapiens a qual pertencemos, e o importante é que somos uma parte da sociedade, uma parte da espécie, seres desenvolvidos sem os quais a sociedade não existe, a sociedade só vive dessas interações.

O Ouvidor-Educador deverá executar um trabalho com vistas a construir a felicidadania (RIOS, 2006) em seu ato de atender, de acolher, de executar suas ações e, mesmo ao mostrar os gargalos institucionais, fomentar espaço no cotidiano da relação pedagógica, para a felicidade e a alegria, no que for possível, por óbvio, tomando como referência o bem coletivo, ato que acarreta o reconhecimento do outro, a alteridade, a construção de um espaço de confiabilidade, de transparência, de participação social e, por que não, de desenvolvimento de utopias e de construção de um horizonte futuro mais sólido e eficaz, mediante um espaço de convivência mais humano e acolhedor. 
Ao passo que se propõe que o Ouvidor esteja aberto à apreensão do contorno geográfico, social e econômico de si e do outro, almeja-se uma leitura de mundo que compreenda, por exemplo, a demanda vigente do mercado de trabalho, os novos desafios criados pela globalização, as mudanças no vetor educação, como a implementação de novos recursos tecnológicos nas universidades e, na sequência, nas Ouvidorias.

Projeta-se que o profissional em causa analise o perfil do público a ser atendido, a cultura organizacional da instituição em que está lotado, as novas linhas administrativas de desempenho, as recentes teorias gerenciais e entendimentos sobre seu âmbito de atuação, como, por exemplo, a área de resolução de conflitos, campo que contempla o âmbito da negociação, da mediação ou da conciliação, o que implica treinamento e formação contínua por parte do Ouvidor, com a premissa de otimizar resultados, tornando-se mais consensual e assertivo na seleção do método mais indicado para dada disputa, ressaltando-se a exequibilidade de resolução, a análise dos custos emocionais envolvidos no conflito e, se possível, a harmonização da relação social das partes, buscando humanizar o processo de resolução de problemas. Tudo isso para que ocorra a construção de um espaço de aproximação com o outro e de intermediação com a comunidade que lhe é subjacente.

\section{O PAPEL DAS TECNOLOGIAS NO ÂMBITO DAS OUVIDORIAS}

Nesse viés, constata-se que, atualmente, a implementação de novas tecnologias é uma das soluções encontradas para suprir algumas das grandes demandas de trabalho nas Ouvidorias: a necessidade de produção de relatórios para a administração superior, decanatos, assessorias de planejamento ou para outras áreas, o registro das manifestações e, ainda, para que possam contribuir para a simplificação de procedimentos nos seus espaços de atuação e, de forma plena, deem visibilidade às ações e interlocuções das Ouvidorias.

Nessa direção, pontua-se que, conforme RODRIGUES (2001), a denominação de tecnologia é definida como "tecno", ou seja, representa o saber fazer, e "logia" proveniente de estudo ou razão. Desta feita, implica o motivo, a razão do saber fazer, e pode ser classificada de acordo com várias funcionalidades e subdividida em várias dimensões, saberes e habilidades, entre outros aspectos.

Outrossim, uma grande preocupação dos Ouvidores com esta modalidade de estruturação das Ouvidorias certamente é a questão pedagógica, pois muito se tem privilegiado os recursos tecnológicos digitais e os materiais impressos e audiovisuais, e pouco interesse se tem notado no que concerne à discussão pedagógica (VALENTE, 2003). Vale ainda ressaltar, no âmbito pedagógico, a diferença entre informação e construção do conhecimento.

Nesse sentido, privilegiando uma educação baseada no conhecimento, VALENTE (2003, p. 139) afirma que "é ilusório, para não dizer enganoso, esperar que uma atividade educacional que privilegie a transmissão de informação tenha como produto a construção de conhecimento". No caso específico das novas tecnologias essa distinção ganha força, uma vez que a interação entre o público (o cidadão) e a Ouvidoria é, por conseguinte, intermediada por uma tecnologia, sendo 
de suma importância para criar condições de construção de conhecimento, e não apenas para transmitir informações. Daí a importância de se estabelecer a melhor abordagem pedagógica para se alcançar os resultados desejados.

Para entender o que é esse "olhar tecnológico", é fundamental distinguir conhecimento x informação e ensino $x$ aprendizado. Isto é, diferenciar esses conceitos para que as novas tecnologias tenham validade como mecanismo na relação de aprendizagem e alcancem seus objetivos.

Diversos autores definem informação como uma organização do dado de acordo com certos padrões significativos (DAVIS \& BOTKIN,1994 apud VALENTE, 2003). Quer dizer, a partir do momento que as pessoas passam informações entre si, o dado deixa de ser "uma coisa sem significado" para adquirir valor significativo. E, quando essa informação sofre um processo de compreensão e interpretação, passa a ser o conhecimento, que é de cada um, impossível de ser passado, conforme VALENTE (2003).

A relação subjacente ao processo de ensino é entendida como "colocar signos", isto é, depositar informações, o que seria equivalente ao que Paulo Freire define como educação bancária. O conceito de aprender é a construção de novos conhecimentos por parte do indivíduo e não apenas ser este apenas um depositário de informações. É este o ponto de defesa deste artigo, que o Ouvidor-Educador deve compreender e participar dos processos de construção de novos conhecimentos no ambiente em que está inserido, a fim de que possa participar ativamente das discussões quanto à elaboração de novas metodologias, de novos indicadores para a execução, a avaliação e o monitoramento das políticas públicas que, muitas vezes, são objetos das críticas e das manifestações que lhe chegam e, ainda, dos próprios sistemas que o rodeiam.

Ressalta-se, dessa forma, que o conhecimento possui papel de destaque na formação econômica e social do País e, em particular, dos espaços universitários e na formação dos indivíduos da sociedade, por intermédio da função social da própria universidade, seu ato de educar, de formar cidadãos com formação humana e cultural integral.

Na prática, o Ouvidor-Educador cônscio, que visa a uma educação de qualidade e, sobretudo, a uma Ouvidoria que atenda às reais demandas que lhe são pertinentes, deverá estar "antenado" com as novas modalidades tecnológicas, o que implica estar preparado para os desafios de sua

profissão e do universo que a cerca. É bem verdade que essa premissa norteia outra proposição importante: a necessidade da formação continuada do ator social em questão, colocando-o na condição de eterno aprendiz.

\section{O OUVIDOR-EDUCADOR E A FORMAÇÃO CONTINUADA}

A questão da competência da ação do Ouvidor-Educador em sua área de atuação tem sido objeto de várias propostas de programas de capacitação e/ou certificação que enfatizam a aquisição de conteúdos, as habilidades, as competências, além de reflexões a respeito da prática pedagógica na relação com o cidadão e no contexto do atendimento, bem como abarcam a construção de fluxos de trabalho e de processos e propiciam distinto grau de conhecimento e de maturidade sobre o fluxograma e o organograma da instituição na qual esteja inserido, entre múltiplos outros aspectos. 
Desta feita, a fim de que ocorra a aprendizagem nessa área e a formação continuada por parte deste seleto grupo de sujeitos, é importante fomentar a capacitação de técnicos com boa cultura geral e domínio de conhecimentos específicos, que devem estudar e elaborar meios para fazê-lo com eficácia, ou seja, um multiespecialista, o que, certamente, enseja formação sólida e contínua, em particular em função da era da informação tecnológica em que se vive.

Além do fato de que a relação entre a teoria e a prática resulta na necessidade de constante aperfeiçoamento e na elaboração e execução de pesquisas que contemplem as situações reais às quais o Ouvidor esteja inserido, o Ouvidor-Educador deve ser também um Ouvidor-Pesquisador, sujeito que almeja a construção de um olhar reflexivo acerca da ação humana, em suas mais diversas dimensões: histórica, social, humana, econômica, entre outras.

Nessa direção, a competência profissional do Ouvidor está diretamente relacionada com o seu comprometimento com os estudos e a consciência de que estará na constante condição de eterno aprendiz, mediante a edificação e a busca de um itinerário formativo eficiente e contínuo.

Há que se registrar também que formação continuada não envolve tão somente o desejo e a postura do Ouvidor em fazê-la. É mister que se tenha uma estrutura social e um espaço de trabalho que contemple políticas públicas de qualidade, que valorizem a formação continuada e, por conseguinte, uma educação de qualidade, com vistas à formação de um sujeito que ora se destaca enquanto interlocutor, ora se destaca enquanto facilitador, e que, na busca de soluções, posiciona-se como sujeito ativo, cônscio e produtor de conhecimento e de respostas, mediante ampla formação técnica e científica, com uma práxis centrada em sua própria autonomia intelectual e no pluralismo de ideias, mediante uma ação construtiva e proativa, conforme cita FREIRE (2018):

Ninguém é sujeito da autonomia de ninguém. Por outro lado, ninguém amadurece de repente, aos vinte e cinco anos. A gente vai amadurecendo todo dia, ou não. A autonomia, enquanto amadurecimento do ser para si, é processo, é vir a ser.

\section{CONSIDERAÇÕES FINAIS}

O exercício da função do Ouvidor-Educador é, antes de qualquer coisa, um ato de amor, no qual, objetivando ser eficiente e eficaz, ele deve reconhecer a importância da sua tarefa, preparar-se com amplitude, esforçar-se, compreender o processo de aprendizagem, planejar bem suas ações, atender com o coração, visto que, em dadas circunstâncias, o número de cidadãos que passaram pelas Ouvidorias (muitas vezes simbólicas) e saíram sem sofrer uma transformação ou obter soluções plenas é considerável, pois nem sempre foram vistos e considerados como sujeitos agentes. O Ouvidor deve visualizar o manifestante e sua demanda sempre como a razão de seu plano, de seu projeto de ação e atuação.

À medida que os atuais Ouvidores fazem uma autocrítica e aprendem as lições do passado, organizam-se para alterar o padrão do futuro, sobretudo no que se refere à relação entre a comunidade acadêmica e o cidadão no âmbito das universidades federais, às formas de comunicação, aos aspectos afetivos e emocionais, à dinâmica das manifestações do trabalho pedagógico que o atendimento contempla, entre outras questões que permeiam o referido tema, como o uso de novas 
tecnologias no contexto das Ouvidorias e a formação continuada do Ouvidor e, ainda, da equipe de trabalho. Ouvidor de sucesso, certamente, é um educador interativo e "antenado".

Por fim, a melhor qualidade do atendimento e da escutatória revela-se no prazer com o qual o Ouvidor desenvolve suas atribuições e mediante sua capacidade de entender a leitura de mundo do cidadão, o outro, com a perspectiva de que a construção desse processo é de responsabilidade de todos, assim como a Ouvidoria é marcada como a "Pedagogia da Administração", que se constitui como uma política pública endereçada à constituição da cidadania, ao existenciar-se.

\section{REFERÊNCIAS}

ALVES, Rubem. Instituto Rubem Alves. Disponível em: https://institutorubemalves.org.br/rubem-alves/carpe-diem/cronicas/ escutatoria-3/. Acesso em: 28 jun. 2018.

AYRES, Antônio Tadeu. Como tornar o ensino eficaz. Rio de Janeiro: CPAD, 1995.

AXT, Margarete. Educação (a distância): apontamentos para pensar modos de habitar a sala de aula. Interface Comunic., Saúde, Educ., v. 7, n. 12, p. 143-145, fev. 2003.

FREIRE, Paulo. Pedagogia da Autonomia: saberes necessários à prática educativa. São Paulo: Paz e Terra, 2018.

Pedagogia do Oprimido. São Paulo: Paz e Terra, 2005.

HURST, D.V. E Ele concedeu uns para mestres. Minas Gerais: Betânia S/c, 1994.

MALTEMPI, Marcus Vinicius. Educação a distância... Interface - Comunic., Saúde, Educ., v. 7, n. 12, p. 146, fev. 2003.

MELLO, Guiomar Namo de. Formação inicial de professores para a educação básica: uma (re) visão radical. São Paulo em Perspectiva, v. 14, n. 1, jan./mar., 2000.

MERHY, E. E. Em busca de ferramentas analisadoras das tecnologias em saúde: a informação e o dia a dia de um serviço, interrogando e gerindo trabalho em saúde. In: MERHY, E. E; ONOKO, R. (Org.). Agir em Saúde: um desafio para o público. 2. ed. São Paulo: Hucitec, 2002. p. 113-150.

MORAN, José Manuel. Contribuições para uma pedagogia da educação a distância no ensino superior. Interface Comunic., Saúde, Educ., v. 7, n. 12, p. 147, fev. 2003.

MORIN, Edgar. Os sete saberes necessários à educação do futuro. In: Brasil, Educação e Sociedade, Brasília, MEC, 2014.

RIOS, Terezinha Azerêdo. Compreender e Ensinar: por uma docência da melhor qualidade. São Paulo: Cortez, 2006.

RODRIGUES, A. M. M. Por uma Filosofia da Tecnologia. In: GRINSPUN M. P. S. Z. (Org.). Educação Tecnológica: desafios e perspectivas. 2. ed. São Paulo: Cortez, 2001.

SANTOS, B. S. Para uma sociologia das ausências e das emergências. Revista Crítica de Ciências Sociais, n. 63, p. 237-280, 2002.

A universidade no século XXI. Para uma reforma democrática e emancipatória da Universidade. São Paulo: Cortez, 2004

VALENTE, J. A. Educação a distância no ensino superior: soluções e flexibilizações. Disponível em: <http://www. scielo.br/scielo.php?script=sci_arttext\&pid=S1414-32832003000100010>. Acesso em: 28 jun. 2018. fev. 2003 .

Réplica: os desafios da implantação da EAD. Interface - Comunic., Saúde, Educ., v. 7, n. 12, p. 139-148, 